\title{
Evidence of past recombination events among the genes encoding the Erp antigens of Borrelia burgdorferi
}

\author{
Brian Stevenson, ${ }^{1} \dagger$ Sherwood Casjens ${ }^{2}$ and Patricia Rosa ${ }^{1}$
}

\author{
Author for correspondence: Brian Stevenson. Tel: +1 6063238967. Fax: +1 6062578994. \\ e-mail: lkspic00@pop.uky.edu
}

\footnotetext{
1 Laboratory of Microbial Structure and Function, Rocky Mountain Laboratories, National Institute of Allergy and Infectious Diseases, NIH, Hamilton, MT 59840, USA

2 Division of Molecular Biology and Genetics, Department of Oncological Sciences, University of Utah, Salt Lake City, UT 84132, USA
}

\begin{abstract}
A single Borrelia burgdorferi bacterium may contain six or more different $32 \mathrm{~kb}$ circular plasmids (cp32s). Although these plasmids are homologous throughout much of their sequences, two loci have been identified at which they can vary significantly. The cp32 plasmids and their relatives each contain two adjacent genes, orfC and orf3, that vary in sequence between plasmids found within clones of individual bacteria. The orf $C$ gene product is homologous to proteins involved in partitioning of bacterial plasmids, and the differences at this locus between plasmids may account for their compatibility. The orfC-orf3 loci are located approximately $5 \mathrm{~kb}$ from another variable locus called erp. The orfC-orf3 loci were used as physically linked markers to assess genetic rearrangements in the erp loci; this revealed examples of recombination involving both individual genes and entire erp loci. Recombination of the genes encoding the Erp antigens might contribute to the evasion of the mammalian immune response and could play roles in the establishment and persistence of B. burgdorferi infections in mammalian hosts.
\end{abstract}

Keywords: Borrelia burgdorferi, Lyme disease, erp genes, recombination, plasmids

\section{INTRODUCTION}

The Lyme disease spirochaete Borrelia burgdorferi contains an unusual genome composed of a linear chromosome (Baril et al., 1989; Casjens \& Huang, 1993; Davidson et al., 1992; Ferdows \& Barbour, 1989) and a large number of linear and circular plasmids (Barbour, 1988; Simpson et al., 1990a; Xu \& Johnson, 1995). Among the DNA species found in these bacteria is a family of circular plasmids of approximately $32 \mathrm{~kb}$ in size (cp32-1 through cp32-7 in isolate B31) (Amouriaux et al., 1993; Porcella et al., 1996; Simpson et al., 1990b; Stevenson et al., 1996; Zückert et al., 1994; Zückert \& Meyer, 1996). Restriction site mapping and partial sequencing of these plasmids has indicated that they contain similar nucleotide sequences and gene orders throughout much of their lengths (Casjens et al., 1997; Stevenson et al., 1997). Variants of cp32 plasmids

†Present address: Department of Microbiology and Immunology, MS 415 UKMC, University of Kentucky, Lexington, KY 40536, USA.

The GenBank accession numbers for the orfC-orf3 loci of B31 plasmids cp32-2, cp32-3, cp32-4, cp32-6 and cp32-7 are AF022479, AF022480, AF022481, AF022482 and AF022483, respectively. have also been described, including an $18 \mathrm{~kb}$ truncated form (cp18) and a $56 \mathrm{~kb}$ linear plasmid that contains a large segment of DNA homologous to the cp32 plasmids (lp56) (Casjens et al., 1997; Porcella et al., 1996; Simpson et al., 1990b; Stevenson et al., 1997; Zückert \& Meyer, 1996). Two $8-10 \mathrm{~kb}$ truncated and rearranged members of the cp32 family (cp8.3 and cp9) have also been described (Dunn et al., 1994; Fraser et al., 1997), although they lack many of the genes discussed in this work. Clonal cultures of $B$. burgdorferi containing as many as seven different members of the cp32 plasmid family have been isolated (Casjens et al., 1997), and it is possible that other clones of isolate B31 may contain fewer plasmids or additional, uncharacterized members of the cp32 family. Due to the extensive sequence similarities of the cp32 plasmids, they could not be confidently assembled by the $B$. burgdorfer $i \mathrm{~B} 31$ genome sequencing project of the Institute for Genomic Research (TIGR) (Fraser et al., 1997), and their complete sequences have not yet been published.

Many of the cp32 family of plasmids are compatible with each other and would therefore be expected to utilize different segregation proteins (Novick, 1987). 
Two putative genes, orfC and orf3, were found to be adjacent to each other on two of the cp32s and the lp56 of B. burgdorferi isolate B31 (Casjens et al., 1997; Zückert \& Meyer, 1996) and on the cp18 of isolate N40 (Stevenson et al., 1997), and these four orfC-orf3 loci are heterogeneous in sequence (Stevenson et al., 1997; Zückert \& Meyer, 1996). The deduced Orf3 proteins are not homologous to any other previously characterized protein. It has been previously noted that the orfC genes are similar to proteins that are required for efficient partitioning of low-copy-number plasmids of other bacteria (Barbour et al., 1996; Zückert \& Meyer, 1996), such as the ParA and SopA proteins encoded by the Escherichia coli plasmids P1 and F, respectively (Abeles et al., 1984; Ogura \& Hiraga, 1983). Due to the predicted similarities of the OrfC proteins with these plasmid segregation proteins, we postulate that each $\mathrm{cp} 32$ family member within a single bacterium might carry different orf $C$ genes and we have now characterized the orfC-orf3 loci of all the known cp32 plasmids that can be carried by $B$. burgdorferi isolate $\mathrm{B} 31$.

The cp32 plasmids also encode members of a family of surface-exposed, membrane-bound lipoproteins we have called Erp proteins (Casjens et al., 1997; Stevenson et al., 1996). Shortly after mammals become infected with $B$. burgdorferi, antibodies are produced against a small number of bacterial proteins (Craft et al., 1986; Engstrom et al., 1995; Wilske et al., 1986), including homologues of the Erp proteins (Akins et al., 1995; Nguyen et al., 1994; Stevenson et al., 1995, 1998; Suk et al., 1995; Wallich et al., 1995). Individual spirochaetes may be capable of producing a large number of different Erp proteins (Casjens et al., 1997; Stevenson et al., 1996). Genes encoding Erp homologues from several $B$. burgdorferi isolates have been sequenced (Akins et al., 1995; Lam et al., 1994; Marconi et al., 1996; Stevenson et al., 1996, 1998; Suk et al., 1995; Wallich et al., 1995), and often show a variability of sequence suggestive of past recombination events among these genes. However, the multiplicity and similarity of the cp32 plasmids have made it impossible to determine whether the variation seen among members of the erp family is due to recombination events or reflects separately evolving gene sequences on a very large number of homologous plasmids. In this study we used the distinctive orfC-orf3 loci of the cp32 plasmids as physically linked markers to analyse the relationships between erp loci and we found evidence of historical recombination events among the erp gene family.

\section{METHODS}

Bacterial strains and culture. B. burgdorferi were grown at $34^{\circ} \mathrm{C}$ in liquid BSK-H medium (Sigma) supplemented with $6 \%$ rabbit serum (Sigma). Isolate B31 is the type strain of $B$. burgdorferi (ATCC 35210), originally isolated from an infected tick collected on Shelter Island, New York (Burgdorfer et al., 1982). Two previously described clones of B31 were used in this work: B31-4a, cloned from a lowpassage culture and infectious in laboratory mice, and B31-e1, cloned from a culture that has been maintained in the laboratory for several years and is no longer infectious in mice (Casjens et al., 1997). Isolate N40 was originally cultured from an infected tick collected in Westchester County, New York (Barthold et al., 1993).

DNA cloning and sequencing. Plasmid DNA from $100 \mathrm{ml}$ cultures of $B$. burgdorferi or E. coli, grown in BSK-H or terrific broth (Maniatis et al., 1982), respectively, were prepared using Qiagen Midi plasmid purification kits following the manufacturer's recommendations. A previously described recombinant E. coli plasmid containing an EcoRI fragment of the B31 cp32-3 (Casjens et al., 1997) was used to determine the orfC and orf 3 sequences of $\mathrm{cp} 32-3$.

The orfC-orf3 loci of the B31 cp32-2, cp32-4, cp32-6 and cp327 were amplified by PCR from purified B31 plasmids using an oligonucleotide complementary to the conserved orf 2 gene in combination with an oligonucleotide primer complementary to a specific DNA sequence within the erp locus of each plasmid (Table 1). DNA fragments of cp32-2 and cp32-4 were amplified from clone B31-e1, and fragments of cp32-6 and cp32-7 were amplified from clone B31-4a. PCR conditions in a DNA Thermal Cycler (Perkin-Elmer) consisted of 25 cycles of $94^{\circ} \mathrm{C}$ for $1 \mathrm{~min}, 50^{\circ} \mathrm{C}$ for $1 \mathrm{~min}$ and $65^{\circ} \mathrm{C}$ for $6 \mathrm{~min}$. PCR reaction products [both uncloned and cloned into pCR2.1 (Invitrogen)] were sequenced using a model 370A automated sequencer (Applied Biosystems). DNA and predicted protein alignments were executed using the program CLUSTAL $v$ (Higgins et al., 1992) and phylogenetic trees were constructed using the program MEGALIGN (DNAStar).

Southern blot analysis. DNA electrophoresis, blotting and hybridization with radiolabelled probes was carried out as described previously (Casjens \& Huang, 1993; Casjens et al., 1997). Using the oligonucleotides listed in Table 1 , probes specific for the orfC genes of plasmids cp32-2, cp32-3, cp32-4, cp32-6 and cp32-7 were produced by PCR amplification from cloned DNA fragments that included each gene. Reaction conditions in a DNA Thermal Cycler (Perkin-Elmer) consisted of 25 cycles of $94^{\circ} \mathrm{C}$ for $1 \mathrm{~min}, 50^{\circ} \mathrm{C}$ for $30 \mathrm{~s}$ and $72^{\circ} \mathrm{C}$ for 1 min. PCR reaction products were diluted $1: 100$ in distilled water and subjected to a second round of PCR amplification.

Accession numbers of previously described genes and proteins. The GenBank accession numbers of the B31 erpAB2, $\operatorname{erp} C D, \operatorname{erp} G, \operatorname{erpH}, \operatorname{erplJ}, \operatorname{erpK}, \operatorname{erp} L M$ and $\operatorname{erpX}$ loci are U78764, U44914, U42598, U44913, U72996, U72997, U72998 and AF020657, respectively (Casjens et al., 1997; Stevenson et al., 1996, 1998). The accession numbers of the orfC-orf3 loci of the B31 plasmids cp32-1, cp32-5 and lp56 are X87127, X87202 and X87201, respectively (Casjens et al., 1997; Zückert \& Meyer, 1996). The accession numbers of ospE, ospF and the orfC-orf 3 locus of the $\mathrm{N} 40$ plasmid cp18 are L13924, L13925 and U42599, respectively (Lam et al., 1994; Stevenson et al., 1997). The accession number of the $b b k 2.11$ locus of B. burgdorferi isolate 297 is U30617 (Akins et al., 1995). The accession numbers of the P1 ParA and F SopA proteins are X02954 and U26464, respectively.

\section{RESULTS AND DISCUSSION}

\section{Characterization of the orfC and orf3 genes from the B31 cp32 plasmids}

We have previously identified eight plasmids in cultures of $B$. burgdorferi isolate B31 (seven different cp32s and lp56) that are largely homologous to one another (Casjens et al., 1997). Since the previously sequenced 
Table 1. Oligonucleotides used in this work

\begin{tabular}{|c|c|c|}
\hline Use & $\begin{array}{c}\text { Our } \\
\text { designation }\end{array}$ & Sequence $\left(5^{\prime}\right.$ to $\left.3^{\prime}\right)$ \\
\hline \multicolumn{3}{|c|}{$\begin{array}{l}\text { Amplification of orf } 2 \\
\text { to erp locus }\end{array}$} \\
\hline \multirow[t]{2}{*}{ cp32-2 } & B-1 & CAACAAAGTTTTATTTAGTATG \\
\hline & E-190 & TTTTCTATTTTTGTTATTATCTCC \\
\hline \multirow[t]{2}{*}{$\operatorname{cp} 32-4$} & B-1 & CAACAAAGTTTTATTTAGTATG \\
\hline & E-404 & ATTCATTCTTAGGGTTTTCATATC \\
\hline \multirow[t]{2}{*}{ cp32-6 } & B-3 & TTTATGGGAAAAAATACCCGG \\
\hline & E-504 & CACTTTTAGGATCCGACTTCTC \\
\hline \multirow[t]{2}{*}{$\operatorname{cp} 32-7$} & B-3 & TTTATGGGAAAAAATACCCGG \\
\hline & E-704 & CGCCTTGAGTTTTCCCAGTTGAAG \\
\hline \multicolumn{3}{|l|}{$\begin{array}{l}\text { Construction of } \\
\text { orfC-specific } \\
\text { probes }\end{array}$} \\
\hline \multirow[t]{2}{*}{$\mathrm{cp} 32-2$ and $\mathrm{cp} 32-7$} & E-311 & GGAATGTATTAATTGATAATTCAG \\
\hline & E-328 & GCGAAATAAATAGTGCCTTATGGG \\
\hline \multirow[t]{2}{*}{ cp32-3 } & CP3-1 & TTACGAAAAAATAGAAAAACTAGG \\
\hline & CP3-2 & TTTCCACTGCCCACTTTTCAGCCG \\
\hline \multirow[t]{2}{*}{ cp32-4 } & CP4-1 & AGATCCTCAAAATAGTTTAACCAG \\
\hline & CP4-2 & TTAATATTGGCAGAGAGTCTACAG \\
\hline \multirow[t]{2}{*}{ cp32-6 } & CP6-1 & GACTTTACATAGTATAAATGCTTTTGG \\
\hline & CP6-2 & TCTCGTTATTATAAAATAAGTAGG \\
\hline
\end{tabular}

Table 2. The known members of the cp32 plasmid family of isolates B31 and N40 and the designations of their erp/ospEF loci

\begin{tabular}{|lll|}
\hline Isolate & Plasmid & Gene(s) \\
\hline B31 & $\mathrm{cp} 32-1$ & $\operatorname{erpA}$, erpB2 \\
& $\mathrm{cp} 32-2$ & $\operatorname{erpC}$ erpD \\
& $\mathrm{cp} 32-3$ & $\operatorname{erpG}$ \\
& $\mathrm{cp} 32-4$ & $\operatorname{erpH}$ \\
& $\mathrm{cp} 32-5$ & $\operatorname{erpl}, \operatorname{erpJ}$ \\
& $\mathrm{cp} 32-6$ & $\operatorname{erpK}$ \\
& $\mathrm{cp} 32-7$ & $\operatorname{erpL}, \operatorname{erpM}$ \\
& $\mathrm{lp} 56$ & $\operatorname{erpX}$ \\
$\mathrm{N} 40$ & $\mathrm{cp} 18$ & $\operatorname{osp} E$, ospF \\
\hline
\end{tabular}

orfC-orf3 genes of cp32-1 and cp32-5 (Zückert \& Meyer, 1996) are located approximately $5 \mathrm{~kb} 5^{\prime}$ of the erp loci of these two plasmids (Casjens et al., 1997), we reasoned that the remaining cp32 plasmids would probably contain orfC and orf 3 homologues in similar locations. Consistent with our hypothesis, we were able to identify orfC-orf3 loci in DNA fragments that included each of the other erp loci (Table 2).

A previously cloned EcoRI fragment of cp32-3 isolated from a library of B. burgdorferi clone B31-e1 plasmid fragments encompassed the region predicted to contain the orfC-orf3 locus (Casjens et al., 1997), which we confirmed by sequencing. The remaining orfC-orf 3 loci, from plasmids cp32-2, cp32-4, cp32-6 and cp32-7, were obtained by PCR amplification from B31 plasmid DNA. Another putative gene, orf2, is located immediately $5^{\prime}$ of the orfC gene on cp32-1, cp32-3, cp32-5 and lp56 (see Fig. 3) (this work; Zückert \& Meyer, 1996). Unlike orfC and orf 3 , the previously known orf 2 genes have more than $95 \%$ identical nucleotide sequences (Zückert \& Meyer, 1996). We used oligonucleotides based on conserved sequences of the orf 2 genes, in combination with oligonucleotides complementary to specific sequences located within each known B31 erp locus, to amplify the DNA spanning the region between the orf 2 and erp genes from cp32-2, $-4,-6$ and -7 . These DNA fragments were partially sequenced, which revealed that each contained the appropriate erp locus on one end and an orfC-orf3 locus on the other end.

We previously constructed detailed maps for each member of the B31 cp32 plasmid family that locate the cleavage sites of 20 different restriction endonucleases, and have found that each cp32 plasmid and lp56 has a unique cleavage pattern (S. Casjens, unpublished results; Casjens et al., 1997) To confirm that we had identified the correct orfC-orf3 genes from each cp32 plasmid, we used probes specific for each orfC-orf3 locus in Southern hybridization studies. In all cases, the restriction patterns obtained using the orfC-orf 3 probes were identical to those found previously using other probes specific for each plasmid. The same results were obtained when hybridizing to DNA purified from either the high-passage, non-infectious clone B31-e1, the lowpassage, infectious clone $\mathrm{B} 31-4 \mathrm{a}$ or $\mathrm{B} 31-\mathrm{MI}$, the 


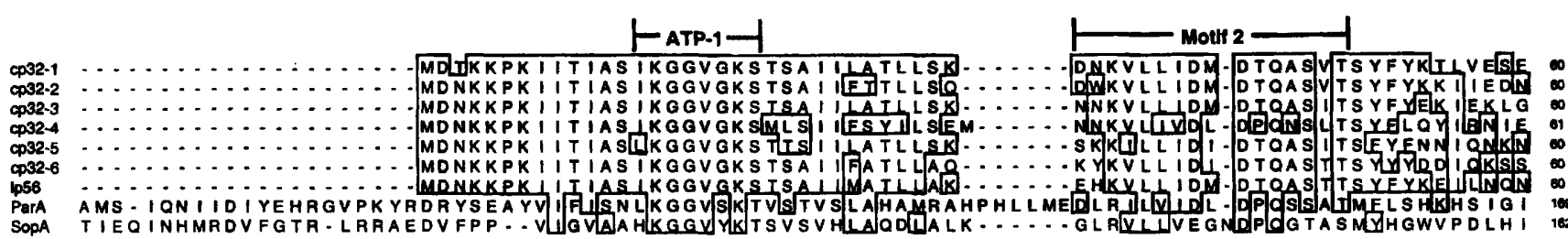

FATP-2 1
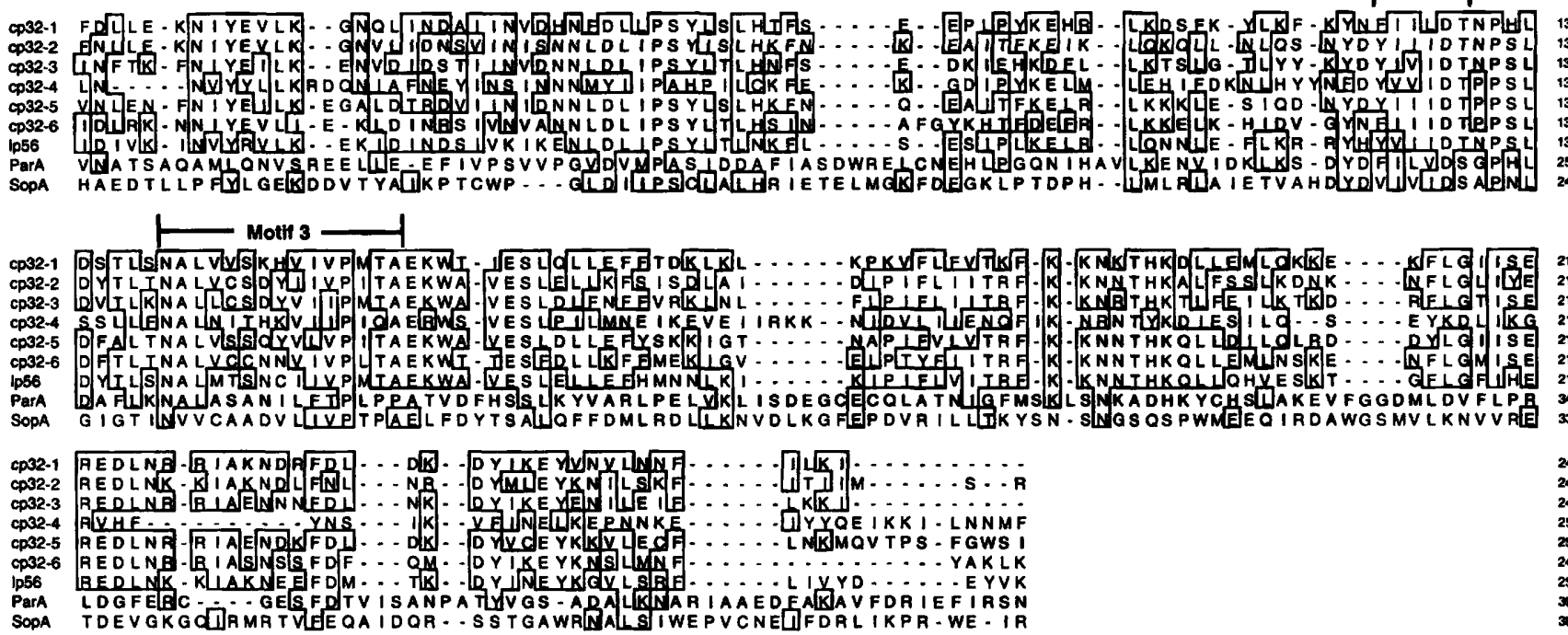

Fig. 1. Comparisons of the predicted amino acid sequences of OrfC proteins encoded on the B31 cp32 and Ip56 plasmids and of the ParA and SopA proteins encoded on the $E$. coli plasmids $P 1$ and $F$, respectively. The predicted OrfC protein sequence of $\mathrm{cp} 32-7$ is identical to that of $\mathrm{cp} 32-2$. The putative ATP-binding sites (ATP-1 and ATP-2) and Motifs 2 and 3 are as described by Motallebi-Veshareh et al. (1990). For brevity the first 82 amino acid residues of both ParA and SopA have not been included.

uncloned cuture that has been partially sequenced by TIGR (Fraser et al., 1997). We conclude that the PCR fragments we obtained accurately reflect the orfC-orf3 and erp locus arrangements on the B. burgdorferi $\mathrm{B} 31$ cp32 plasmids.

Comparing the predicted OrfC proteins of plasmids cp32-1 through cp32-6 and of $1 \mathrm{p} 56$ indicated that these proteins all contain regions of similarity with the ParA and SopA proteins of E. coli plasmids $\mathrm{P} 1$ and $\mathrm{F}$ (Fig. 1). The ParA and SopA proteins are essential for accurate segregation of these low-copy-number plasmids between daughter cells following bacterial cell divison (Abeles $\boldsymbol{e t}$ al., 1984; Austin \& Abeles, 1983a, b; Martin et al., 1991; Motallebi-Veshareh et al., 1990). All the predicted OrfC proteins contain sequences homologous to the conserved ATP-1 and ATP-2 motifs that are involved in ATP binding and hydrolysis by the plasmid segregation proteins (Motallebi-Veshareh et al., 1990; Watanabe $\boldsymbol{e t}$ al., 1992). Homology is also found to the semi-variable motifs (Motifs 2 and 3, Fig. 1) that are postulated to be involved in binding accessory proteins or membrane attachment sites (Motallebi-Veshareh et al., 1990). The predicted OrfC proteins of the $B$. burgdorferi plasmids also exhibit a large degree of sequence variation (Fig. 1, Table 3) that is consistent with that observed among the segregation proteins of the $\mathrm{P} 1, \mathrm{~F}$ and other, similar plasmids (Fig. 1) (Motallebi-Veshareh et al., 1990). This divergence presumably allows specific recognition of other plasmid segregation proteins (Motallebi-Veshareh et al., 1990). If the OrfC proteins function in plasmid partition, the variation among them may account for the compatibility of the numerous $\mathrm{cp} 32 \mathrm{~s}$ and related plasmids found in isolate B31.

In contrast to the heterogeneity seen among the other plasmids of $\mathrm{B} 31, \mathrm{cp} 32-7$ contains orfC and orf3 genes that are nearly identical to those located on cp32-2, differing by only $4 \mathrm{bp}$ over a stretch of $1311 \mathrm{bp}$ (Table $3)$. These four differences do not alter the amino acid sequences, so the OrfC and Orf3 proteins of $\operatorname{cp} 32-2$ and cp32-7 are predicted to be indistinguishable (Table 3 ). If our hypothesis about the OrfC proteins being involved in plasmid partitioning is correct, then cp32-2 and cp327 would be incompatible with one another. Consistent with this idea, none of the clonal derivatives of B31 we have obtained contain both cp32-2 and cp32-7 (Casjens et al., 1997). It has been suggested that the original B31 isolate may have been a mixed population of closely related bacteria (Saint Girons \& Davidson, 1992), and some of these may have contained $\mathrm{cp} 32-2$ while others contained cp32-7. Additional studies will be required to conclusively identify the compatibility determinants of the many $B$. burgdorferi plasmids. 
Table 3. Similarities between orfC-orf3 loci and predicted OrfC and Orf3 proteins of each cp32 and Ip56 plasmid of $B$. burgdorferi B31 and cp18 of B. burgdorferi N40

The three values given for each comparison represent the percentage identity between the indicated pairs of sequences in the following order: orfC-orf 3 locus nucleotides/OrfC amino acids/Orf3 amino acids.

\begin{tabular}{|c|c|c|c|c|c|c|c|c|}
\hline & \multicolumn{7}{|c|}{ B31 } & \multirow{2}{*}{$\begin{array}{l}\text { N40 } \\
\text { cp18 }\end{array}$} \\
\hline & cp32-2 & cp32-3 & cp32-4 & cp32-5 & cp32-6 & cp32-7 & lp56 & \\
\hline cp32-1 & $65 / 62 / 62$ & $65 / 64 / 63$ & $44 / 31 / 41$ & $61 / 58 / 60$ & $62 / 59 / 57$ & $65 / 62 / 62$ & $61 / 60 / 58$ & $65 / 62 / 62$ \\
\hline cp32-2 & & $64 / 65 / 60$ & $43 / 33 / 40$ & $61 / 61 / 58$ & $59 / 57 / 53$ & $99 \cdot 7 / 100 / 100$ & $64 / 63 / 59$ & $99 \cdot 7 / 100 / 100$ \\
\hline cp32-3 & & & $46 / 32 / 39$ & $64 / 62 / 64$ & $62 / 61 / 56$ & $64 / 65 / 60$ & $63 / 60 / 63$ & $64 / 65 / 60$ \\
\hline cp32-4 & & & & $46 / 32 / 47$ & $46 / 28 / 42$ & $43 / 33 / 40$ & $45 / 31 / 37$ & $43 / 33 / 40$ \\
\hline cp32-5 & & & & & $60 / 58 / 63$ & $61 / 61 / 58$ & $58 / 56 / 53$ & $61 / 61 / 58$ \\
\hline cp32-6 & & & & & & $59 / 57 / 53$ & $59 / 58 / 50$ & $59 / 57 / 53$ \\
\hline cp32-7 & & & & & & & $64 / 63 / 59$ & $100 / 100 / 100$ \\
\hline lp56 & & & & & & & & $64 / 63 / 59$ \\
\hline
\end{tabular}

Table 4. Similarities between the B31 erp genes and their protein products and the related N40 ospE and ospF and 297 bbk2.11 genes and proteins

Similarities are expressed as percentage identical nucleotides of the genes/identical amino acids of the proteins.

\begin{tabular}{|c|c|c|c|c|c|c|c|c|c|c|c|}
\hline & \multicolumn{8}{|c|}{ B31 } & \multicolumn{2}{|c|}{ N40 } & \multirow{2}{*}{$\begin{array}{c}297 \\
\text { bbk2.11 }\end{array}$} \\
\hline & $\operatorname{erp} B 2 / J$ & $\operatorname{erp} C$ & $\operatorname{erp} D$ & $\operatorname{erp} G$ & $\operatorname{erp} K$ & $\operatorname{erp} L$ & $\operatorname{erp} M$ & $\operatorname{erp} X$ & $\operatorname{osp} E$ & ospF & \\
\hline $\operatorname{erp} A / I$ & $35 / 19$ & $83 / 77$ & $34 / 21$ & $34 / 21$ & $35 / 19$ & $36 / 23$ & $37 / 19$ & $41 / 24$ & $85 / 81$ & $34 / 18$ & $36 / 23$ \\
\hline $\operatorname{erp} B 2 / J$ & & $34 / 20$ & $71 / 62$ & $49 / 32$ & $40 / 26$ & $38 / 22$ & $71 / 58$ & $56 / 38$ & $34 / 18$ & $39 / 23$ & $38 / 21$ \\
\hline $\operatorname{erp} C$ & & & $35 / 20$ & $34 / 19$ & $36 / 20$ & $38 / 22$ & $37 / 18$ & $36 / 21$ & $88 / 77$ & $33 / 19$ & $37 / 23$ \\
\hline $\operatorname{erp} D$ & & & & $49 / 33$ & $42 / 25$ & $37 / 24$ & $67 / 58$ & $53 / 35$ & $32 / 20$ & $38 / 25$ & $38 / 23$ \\
\hline $\operatorname{erp} G$ & & & & & $51 / 36$ & $50 / 34$ & $48 / 33$ & $45 / 28$ & $32 / 20$ & $48 / 30$ & $52 / 33$ \\
\hline $\operatorname{erpK}$ & & & & & & $55 / 39$ & $41 / 28$ & $41 / 25$ & $34 / 18$ & $58 / 43$ & $64 / 49$ \\
\hline $\operatorname{erp} L$ & & & & & & & $39 / 17$ & $40 / 24$ & $35 / 21$ & $76 / 67$ & $83 / 80$ \\
\hline $\operatorname{erp} M$ & & & & & & & & $61 / 47$ & $35 / 19$ & $38 / 22$ & $40 / 22$ \\
\hline $\operatorname{erp} X$ & & & & & & & & & $38 / 22$ & $40 / 17$ & $41 / 25$ \\
\hline $\operatorname{osp} E$ & & & & & & & & & & $34 / 17$ & $35 / 23$ \\
\hline$o s p F$ & & & & & & & & & & & $76 / 63$ \\
\hline
\end{tabular}

\section{Related orfC-orf3 loci of another B. burgdorferi isolate}

The orfC and orf 3 genes of cp32-7 are identical to those of $\mathrm{cp} 18$, an $18 \mathrm{~kb}$ truncated member of the cp32 family found in B. burgdorferi isolate N40 that contains the ospEF locus, a homologue of the B31 erp loci (Table 2) (Lam et al., 1994; Stevenson et al., 1997). Since the OrfC and Orf3 proteins of $\mathrm{cp} 18$ are predicted to be identical to those of cp32-2 and cp32-7, we conclude that at least this portion of these three plasmids shares a recent common ancestor. We have previously found that all $B$. burgdorferi sensu stricto isolates examined contained plasmids of the cp32 family (Casjens et al., 1997). It is unknown whether other bacteria besides N40 contain any such close relatives of the B31 cp32 plasmids. B31 was isolated on Shelter Island, New York (Burgdorfer et al., 1982) while $\mathrm{N} 40$ was isolated several years later in Westchester County on the New York mainland
(Barthold et al., 1993). Analyses of the cp32 orfC-orf3 loci of different isolates could serve as markers of how widespread these plasmids are among Lyme disease bacteria and whether they can be transmitted horizontally.

\section{orfC-orf3 genes as markers of genetic drift versus recombination}

Most of the B31 erp genes vary considerably in their sequences, as do other members of this gene family that have been identified from other isolates of $B$. burgdorferi (Akins et al., 1995; Casjens et al., 1997; Lam et al., 1994; Marconi et al., 1996; Stevenson et al., 1996, 1998; Suk et al., 1995; Wallich et al., 1995). While this high degree of variation may indicate recombination among these genes, it might also be argued that these differences are due to gradual genetic drift of plasmid sequences that 
(a) N40 cp32-2 orfC-orf3

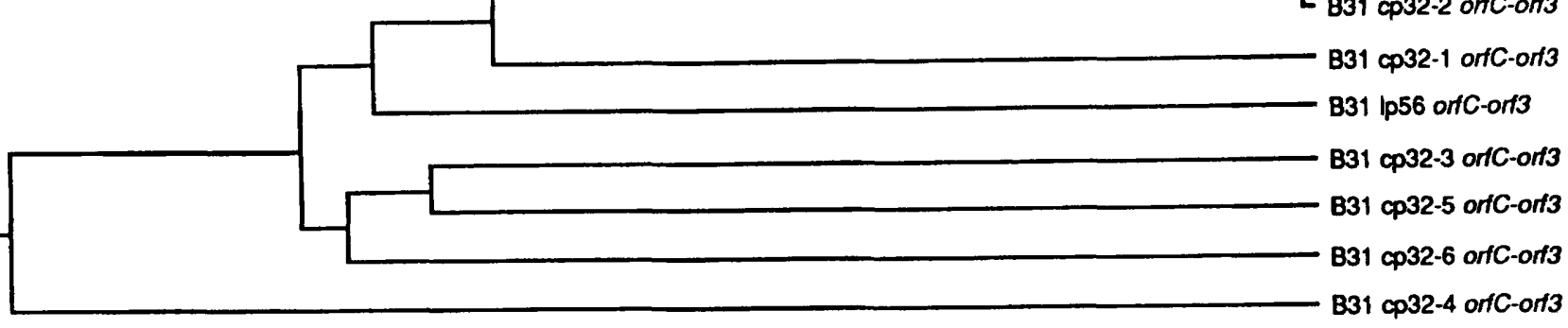

$20 \cdot 7$

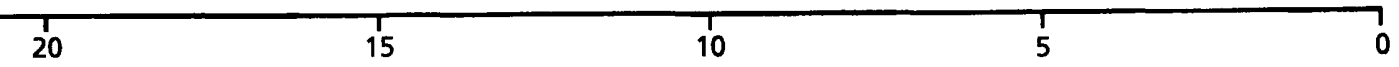

(b)

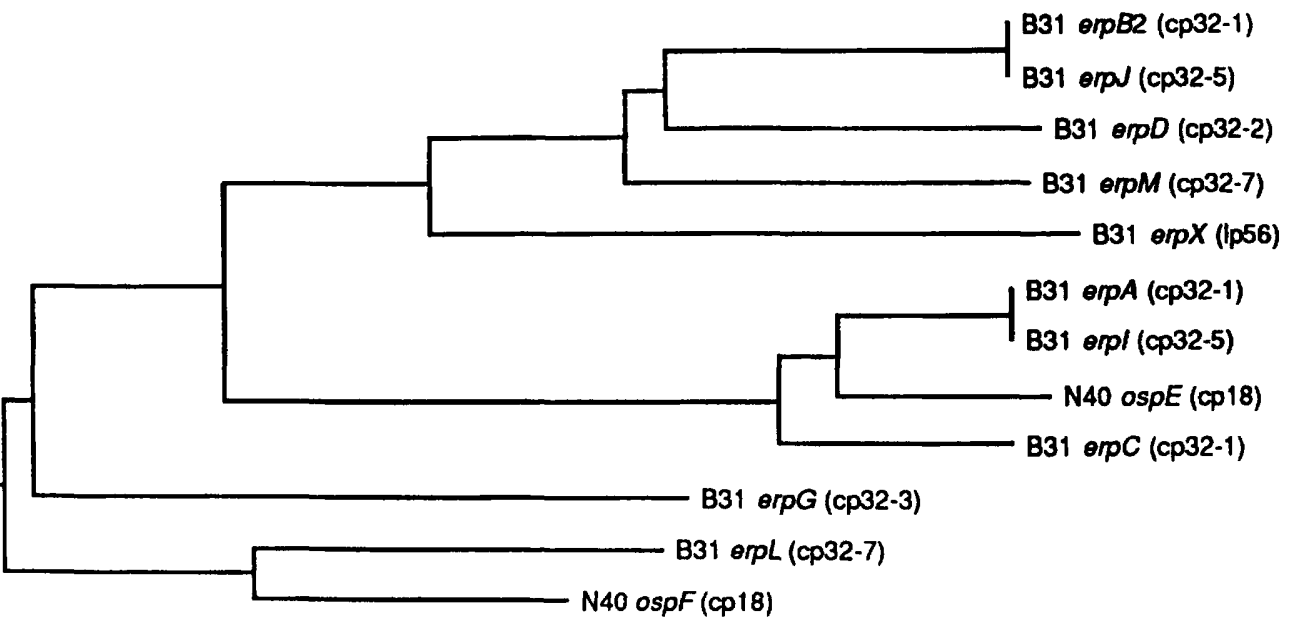

B31 өrpK (cp32-6)

$34 \cdot 3$

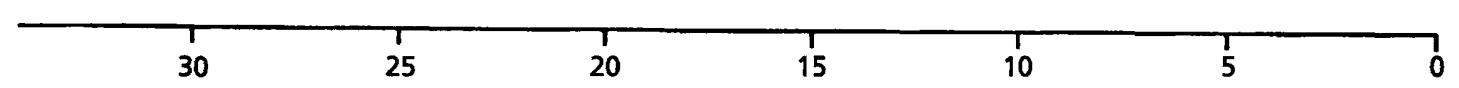

Fig. 2. Unbalanced phylogenetic tree obtained from CLUSTAL V (Higgins et al., 1992) analysis of genes located on the cp32 and Ip56 plasmids of B31 and the Cp18 plasmid of N40. (a) orfC-orf3 genes. (b) B31 erp and N40 ospE and ospF genes. The B31 erpH gene (located on cp32-4) was not included, since this gene is truncated and is significantly shorter than the other erp genes (Stevenson et al., 1996). The scale represents the number of nucleotide substitutions expressed as a percentage of the number of compared nucleotides.

are no longer in genetic contact with one another. The physically linked orfC-orf 3 and erp loci provide a framework for determining whether the erp loci have diverged in isolation or if there have been recent recombination events among the cp32 plasmids.

As an example, plasmid cp32-3 contains erpG, and cp326 contains $\operatorname{erpK}$ (Table 2), which share $51 \%$ identical nucleotides, with the two deduced proteins predicted to contain $36 \%$ identical amino acids (Table 4) (Casjens et al., 1997; Stevenson et al., 1996). The physically linked orfC-orf 3 loci of cp32-3 and cp32-6 are also different between the two plasmids, sharing $62 \%$ identical nucleotides (Table 3). Dendrograms based on orfC-orf3 and erp gene sequences also illustrate the distant relationships of these loci (Fig. 2). The data suggest that cp32-3 and cp32-6 are not closely related members of the cp32 plasmid family, and it is therefore impossible to determine whether variation between $\operatorname{erp} G$ and $\operatorname{erpK}$ is due to recombination or to random mutations that have accumulated since these two plasmids diverged from a presumed common ancestral cp32.

The orfC-orf3 loci of plasmids cp32-1 and cp32-5 are also different from each other, again suggesting a distant relationship (Table 3, Figs $2 a$ and $3 a$ ). Restriction site maps of these two plasmids indicate that they also contain unique sequences at other locations throughout 
(a)

B31 cp32-1

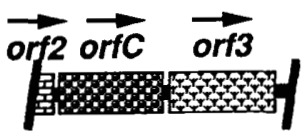

B31 cp32-5

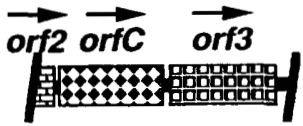

(b)

B31 cp32-2

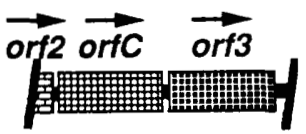

B31 cp32-7
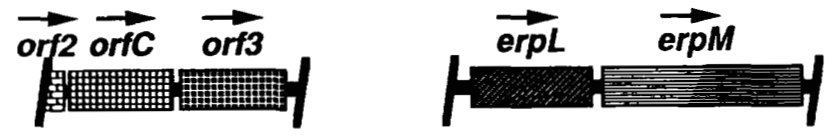

N40 cp18
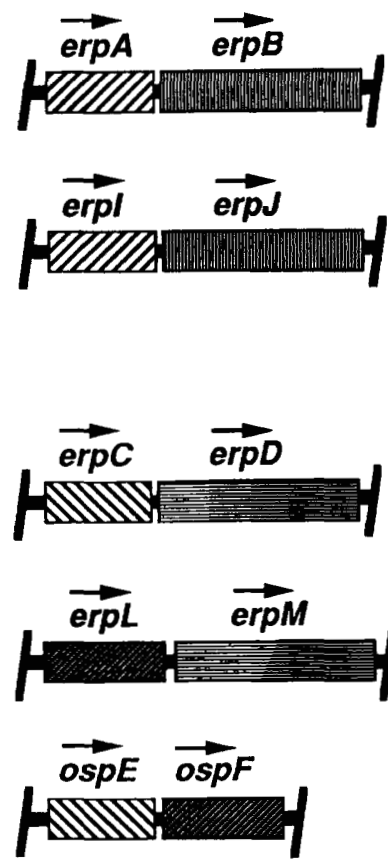

Fig. 3. Diagrams of conserved and nonconserved DNA sequences found on plasmids of the cp32 family, with similar fill patterns indicating similar gene sequences. Arrows indicate the direction of transcription of each gene. (a) B31 plasmids cp32-1 and cp32-5 contain identical erp loci but very different orfC-orf3 loci. (b) B31 plasmids cp32-2 and cp32-7 and N40 plasmid cp18 contain nearly identical orfC-orf3 loci but, in some cases, very different erp homologues. the plasmids (Casjens et al., 1997). In contrast, the $\operatorname{erp} A B 2$ and erplJ loci of cp32-1 and cp32-5, respectively, have identical nucleotide sequences and therefore must be extremely close relatives (Figs $2 \mathrm{~b}$ and $3 \mathrm{a}$ ) (Casjens $e t$ al., 1997; Stevenson et al., 1998). These observations strongly suggest that a recent recombination event gave rise to the current forms of these two plasmids, with a region of DNA that included erpAB2/erplJ replacing the predecessor erp locus of one plasmid.

\section{Recombination within erp loci on closely related plasmids}

The near identity of the orfC-orf 3 loci found on the B31 cp32-2 and cp32-7 plasmids and the N40 cp18 plasmid indicates that at least these regions of the three plasmids are closely related, therefore permitting the comparison of the erpCD, erpLM and ospEF loci for evidence of past recombination events (Fig. 3b). Several genes in these three loci are similar to one another, as would be expected for genes on closely related plasmids. The erpC and $o s p E$ genes, each the first gene of bicistronic operons, share $88 \%$ identical nucleotides and $77 \%$ identical amino acids (Table 4, Figs $2 \mathrm{~b}$ and $4 \mathrm{a}$ ). Similarly, the erpD and erpM genes, the second genes of bicistronic operons, share $67 \%$ identical nucleotides and $58 \%$ identical amino acids (Table 4, Figs $2 \mathrm{~b}$ and $4 b)$. Comparisons of these gene and protein pairs indicate extended regions of similarity with interspersed regions of variation that may represent drift due to gradual accumulation of random mutations (Fig. 4a, b) (Dykhuizen et al., 1993). There are, however, suggestions of past insertion and/or deletion events within these pairs, since in each pair, short lengths of sequence are present in one member of the pair that are absent in the other (Fig. 4a, b).

In contrast, the $\operatorname{erp} L$ gene, the first gene of the $\operatorname{erp} L M$ bicistronic operon, is significantly different from either $\operatorname{erpC}$ or ospE, sharing only $38 \%$ and $35 \%$ identical nucleotides, respectively, and little amino acid identity (Table 4, Figs 2b and 4a). Likewise, ospF, the second gene of the ospEF operon, shares little sequence with either $\operatorname{erpD}$ or $\operatorname{erpM}(38 \%$ identity with both genes) (Table 4, Figs $2 \mathrm{~b}$ and $4 \mathrm{~b}$ ). erpL and $o s p F$, however, share $76 \%$ identical nucleotides and $67 \%$ identical amino acids (Table 4), with extended stretches of identity throughout their lengths (Fig. 4c). This similarity suggests that $\operatorname{erpL}$ and $o s p F$ may be descendants of a common ancestor that recombined into the first or second gene, respectively, of primordial erp $C D$-like loci. The first $452 \mathrm{bp}$ of erpL are also identical to the corresponding region of $b b k 2.11$, a monocistronic erp homologue of $B$. burgdorferi isolate 297 (Akins et al., 1995) (Table 4, Fig. 4c). The location of the bbk2.11 locus in the 297 genome has not yet been determined (Akins et al., 1995), so its other relationships with the B31 and N40 plasmids and erp homologues cannot be analysed at this time.

Although recombination has apparently occurred in natural settings, we have not detected any cp32 rearrangements within laboratory cultures, since both erp gene and cp32 plasmid sequences were found to be virtually identical among cultures of B31 that have been separated for thousands of generations of cultivation (B. Stevenson, unpublished results; Casjens et al., 1997). The only known variation that has occurred in the B31 erp loci during laboratory cultivation is a single base in the $\operatorname{erp} B$ gene of a high-passage, non-infectious culture 
(a) ErpC

OspE

ErpL

ErpC

OspE

ErpL

ErpC

Ospe

ErpL

ErpC

OspE

Erpl

ErpC

OspE

Erpl.

(b) ErpD

ErpM

OspF

ErpD

ErpM

OspF

ErpD

ErpM

Osp

ErpD

ErpM

OspF

ErpD

ErpM

OspF

ErpD

ErpM

ErpD

ErpM

OspF

ErpD

ErpM

OspF

(c) Erpl

OspF

Bbk2.11

ErpL

OspF

Bbk2.11

ErpL

OspF

Bbk2.11

ErpL

OspF

Bbk2.11

ErpL

OspF

Bbk2.11

MNKKMKMF I I CF 1 FAL $S$ SCKNH TL YDGQSNGEA MN KKMKMF IVYAVF四LGACKDHTSYDEQSSGESKVKK IE - - FSKFTVK I KN 50 MNKKMKMF I I CAVFALM ISCKNYASGENL KNSEONLES SEQNVKKTEQE KK 52

KNNS. . . . . N NWA DLGDLVVRKE国D KD KS . . . . GNWTDLGDLVVRKEENG IDT . . . . GLNAG QVEGFLE I LETKDLS KLLDEKDTKE EEKQIQEL KN K I E KLLDS KLT S I EUTY S EY 104 TATFFSLEESE - . - VNNF!

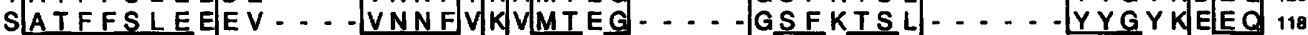
EEKINKI KE KLKGKGLEDKFLELEES L AKKKG EAKKALLQE A K KFEEYKKQV 156

SN ANG IQNKE I TTKIEKIDDFEY . . . . . . . ITFLIGDKIRDSGDKVVEYA 169

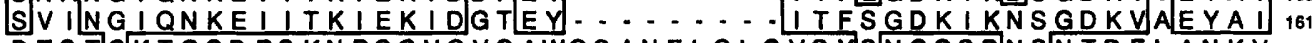
DTS TGK TQGDRS KNRGGVGVQAWQC ANELGLGVSYS NGGSDNS NTDELANKV 208

SLEE

ILDSLLKK I EEELKG IEEDKKE

MNC $/$ AF I ICAVFAL I I SCKNYATSKDLKQNPEGKIKGFLD - . - PT KDKITS 48 MNKKILI IFAVFAL I ISCKNYATGKDDKONAKGK IKGFLDKVLDPAKDK ITS 52 MN KKME I CARFAL IVSCKN YTTS KDL - - - EGSVQD LLES S Q QNAKKTEQE 47

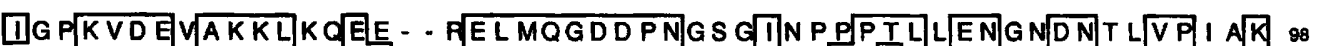

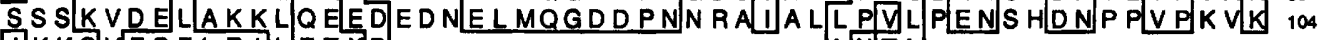

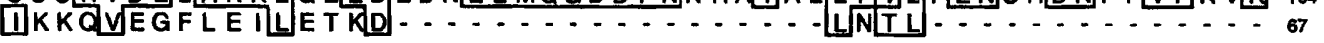

SAEQS AD A

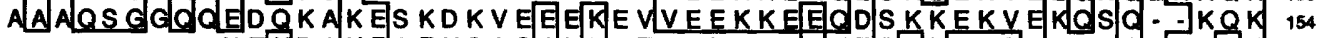

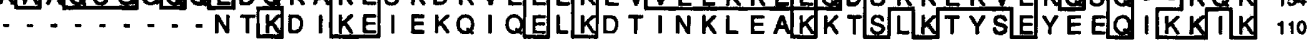
KEERN VKEEKQKQEE - . . . . . . . .

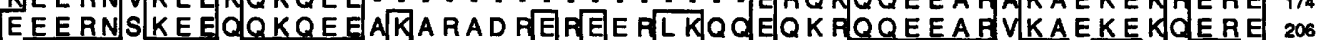

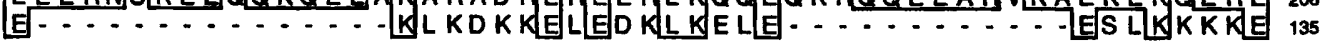

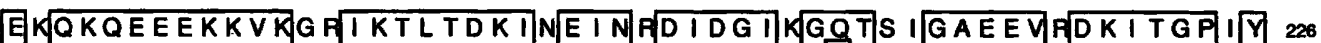
EQQKQEEEKKVKYKIKTLTDK IDE I N KD I DG INGET I VGAEEVIDKI TGPVY 258 ERKKALEDAK-........ KKFE[EF KGQVGSA TLQT]QGQRAGNQGQVGQQ - 176

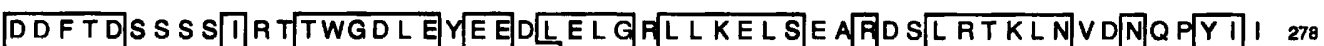
DDFTDGNKALYKTWGDLEDEEGEE L GKLLKELS D TLH NLRTKLNEGNKAYY IV 310

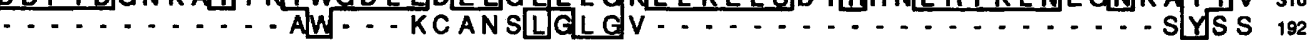

DURS TEPCLKD NVS VSE IKSDLDELKSKLEEVKEYLED KDNFEE I KEYVAGS 330 LEK - - EPN L KEN VNLS D I QSDLELL KS GLEEV K KYFEN EDNFEE I KG Y I EDSS 360

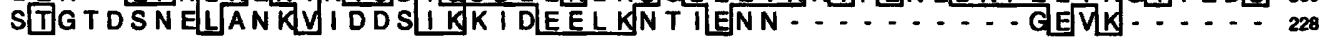

EDNYD E[E]D

- NSY - - K远.

\section{8}

363

230

MNKKMKMF I I CAVFALMISCKNYASGENLKNSEQNLESSEQNVKKTEQE IKK 52 MN KKM- - F I I CADFALIVSCKN VTTSKDLEGSUDDLESS EQNAKKTEQE I KK 50 MNKKMKMFIICAVFALMISCKN YASGEN LKNSEQNLESSEQNVKKTEQE IKK 52

QVEGFLE ILETKDLSKLDEKDTKE IEKQ I QELKNK IEKLDSKKTS IETYSEY 104 QVEGFLE I LETKD LINTLNTKDDKE I EKQ I QELKDTINKLEAKKTSLLT YSEY 102 QVEGFLE ILETKDLSKLDEKDTKE IEKQ IQELKNK IEKLDSKKTS IETYSEY 104

EEKINKIKEKLKGK-GLEDKFKELEESLAKKKGERKKALQEAKQKFEEYAKO 155 EED I EEKINK IKEKLKGK-GLEDKFKELEESLAKKKGERKKALQEAKQKFEELRV 155

VD T S TGKTQGDRS KN RGG VGVWAWC CANELGLGVSYSNGGSDNSNTD ELANK 207 VGSATGQTQGQRAGNQGQVGQQAWKCANSL GLGVS YS S T T TDS N-DLAN 204 VES TTGQTOGQRAGNOGQVGQQ AWKYARELG - . F KNMTGGDNDTS NMANE 203

VIDDSLKKIEEELKG I - - - E-国- D - - KKE

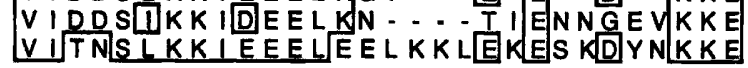

2229

233

Fig. 4. Comparisons of the predicted amino acid sequences of Erp homologues found on plasmids with nearly identical orfC-orf3 loci. (a) ErpC, OspE and ErpL, each encoded by the first gene of a bicistronic operon. (b) ErpD, ErpM and OspF, each encoded by the second gene of a bicistronic operon. (c) Comparison of ErpL, OspF and the Bbk2.11 protein of isolate 297. The sequence of the orfC-orf3 locus that is presumably linked to bbk2.11 is unknown. 
that has mutated from that of both infectious cultures we have studied (B31-4a and B31-MI) (Casjens et al., 1997; Stevenson et al., 1996, 1998). The recombinational rearrangement of the erp genes that we have detected may have taken place within infected mammals, perhaps as part of a mechanism of evading clearance by the immune system. Antibodies directed against the Erp proteins are produced within the first few weeks of mammalian infection (Akins et al., 1995; Das et al., 1997; Nguyen et al., 1994; Stevenson et al., 1995, 1998; Wallich et al., 1995), indicating that they are expressed by $B$. burgdorferi in the early stages of infection. The gene encoding the antigenic $B$. burgdorferi VlsE lipoprotein appears to vary rapidly within infected mice by a homologous recombination mechanism (Zhang et al., 1997). In contrast, the osp $C$ gene, which encodes another antigenic B. burgdorferi lipoprotein (Fuchs et al., 1992), also varies substantially between different isolates of $B$. burgdorferi and exhibits evidence of genetic exchange and recombination (Gibbs $e t$ al., 1996; Jauris-Heipke et al., 1995; Livey et al., 1995; Stevenson \& Barthold, 1994; Theisen et al., 1993, 1995; Tilly et al., 1997), but the $o s p C$ gene is stable in chronically infected laboratory mice, indicating that variation of this gene is not necessary for long-term mammalian infection (Stevenson et al., 1994). Bacteria reisolated from longterm infected animals appear to be antigenically stable at several other loci as well (Barthold, 1993; Persing et al., 1994). Further experiments will determine whether the sequences of the erp genes also undergo recombination within mammals or are stably maintained during chronic mammalian infections.

\section{Conclusions}

We have presented evidence of past recombination events within the plasmids carrying erp genes, using the physically linked orfC-orf 3 locus as a marker of plasmid relatedness. Further analyses may reveal evidence of additional genetic rearrangements. Since a single bacterium may contain several different $\mathrm{cp} 32$ plasmids, each possibly carrying a unique erp locus (Casjens et al., 1997), we cannot speculate on whether these recombination events involved DNA already within a bacterium or if the DNA came from external sources. Homologues of the B31 erp genes have been identified in several other isolates of $B$. burgdorferi (Akins et al., 1995; Lam et al., 1994; Marconi et al., 1996; Suk et al., 1995; Wallich et al., 1995) and characterization of the orfC-orf 3 loci that are physically linked to these genes would enable a more detailed analysis of erp gene family evolution.

\section{ACKNOWLEDGEMENTS}

We thank Nanette Palmer for technical assistance, Daniel Hogan and Stephen Porcella for assistance with the DNA sequencing machinery and tree construction, Kit Tilly, James Bono, Abdallah Elias, Michael Chaussee, Joseph Hinnebusch and Stephen Porcella for constructive comments on the manuscript, and Kelly Matteson and Carole Smaus for secretarial assistance.

\section{REFERENCES}

Abeles, A. L., Snyder, K. M. \& Chattoraj, D. K. (1984). P1 plasmid replication: replicon structure. J Mol Biol 173, 307-324.

Akins, D. R., Porcella, S. F., Popova, T. G., Shevchenko, D., Baker, S. I., Li, M., Norgard, M. V. \& Radolf, J. D. (1995). Evidence for in vivo but not in vitro expression of a Borrelia burgdorferi outer surface protein F (OspF) homologue. Mol Microbiol 18, 507-520.

Amouriaux, P., Assous, M., Margarita, D., Baranton, G. \& Saint Girons, I. (1993). Polymerase chain reaction with the $30-\mathrm{kb}$ circular plasmid of Borrelia burgdorferi B31 as a target for detection of the Lyme borreliosis agents in cerebrospinal fluid. Res Microbiol 144, 211-219.

Austin, S. \& Abeles, A. (1983a). Partition of unit-copy miniplasmids to daughter cells. I. P1 and F miniplasmids contain discrete, interchangeable sequences sufficient to promote equipartition. J Mol Biol 169, 353-372.

Austin, S. \& Abeles, A. (1983b). Partition of unit-copy miniplasmids to daughter cells. II. The partition region of miniplasmid P1 encodes an essential protein and a centromere-like site at which it acts. $J$ Mol Biol 169, 373-387.

Barbour, A. G. (1988). Plasmid analysis of Borrelia burgdorferi, the Lyme disease agent. $J$ Clin Microbiol 26, 475-478.

Barbour, A. G., Carter, C. J., Bundoc, V. \& Hinnebusch, J. (1996). The nucleotide sequence of a linear plasmid of Borrelia burgdorferi reveals similarities to those of circular plasmids of other prokaryotes. J Bacteriol 178, 6635-6639.

Baril, C., Richaud, C., Baranton, G. \& Saint Girons, I. (1989). Linear chromosome of Borrelia burgdorferi. Res Microbiol 140, 507-516.

Barthold, S. W. (1993). Antigenic stability of Borrelia burgdorferi during chronic infections of immunocompetent mice. Infect Immun 61, 4955-4961.

Barthold, S. W., de Souza, M. S., Janotka, J. L., Smith, A. L. \& Persing, D. H. (1993). Chronic Lyme borreliosis in the laboratory mouse. Am J Pathol 143, 959-972.

Burgdorfer, W., Barbour, A. G., Hayes, S. F., Benach, J. L., Grunwaldt, E. \& Davis, J. P. (1982). Lyme disease - a tick-borne spirochetosis? Science 216, 1317-1319.

Casjens, S. \& Huang, W. M. (1993). Linear chromosomal physical and genetic map of Borrelia burgdorferi, the Lyme disease agent. Mol Microbiol 8, 967-980.

Casjens, S., van Vugt, R., Tilly, K., Rosa, P. A. \& Stevenson, B. (1997). Homology throughout the multiple 32-kilobase circular plasmids present in Lyme disease spirochetes. J Bacteriol 179, 217-227.

Craft, J. E., Fischer, D. K., Shimamoto, G. T. \& Steere, A. C. (1986). Antigens of Borrelia burgdorferi recognized during Lyme disease: appearance of a new immunoglobulin $M$ response and expansion of the immunoglobulin $\mathrm{G}$ response late in the illness. J Clin Invest 78, 934-939.

Das, S., Barthold, S. W., Stocker Giles, S., Montgomery, R. R., Telford, S. R. \& Fikrig, E. (1997). Temporal pattern of Borrelia burgdorferi $p 21$ expression in ticks and the mammalian host. J Clin Invest 99, 987-995.

Davidson, B. E., MacDougall, J. \& Saint Girons, I. (1992). Physical map of the linear chromosome of the bacterium Borrelia burgdorferi 212, a causative agent of Lyme disease, and localization of rRNA genes. J Bacteriol 174, 3766-3774.

Dunn, J. J., Buchstein, S. R., Butler, L.-L., Fisenne, S., Polin, D. S., Lade, B. N. \& Luft, B. J. (1994). Complete nucleotide sequence of a circular plasmid from the Lyme disease spirochete, Borrelia burgdorferi. J Bacteriol 176, 2706-2717. 
Dykhuizen, D. E., Polin, D. S., Dunn, J., Wilske, B., Preac-Mursic, V., Dattwyler, R. J. \& Luft, B. J. (1993). Borrelia burgdorferi is clonal: implications for taxonomy and vaccine development. Proc Natl Acad Sci USA 90, 10163-10167.

Engstrom, S. M., Shoop, E. \& Johnson, R. C. (1995). Immunoblot interpretation criteria for serodiagnosis of early Lyme disease. J Clin Microbiol 33, 419-427.

Ferdows, M. S. \& Barbour, A. G. (1989). Megabase-sized linear DNA in the bacterium Borrelia burgdorferi, the Lyme disease agent. Proc Natl Acad Sci USA 86, 5969-5973.

Fraser, C. M., Casjens, S., Huang, W. M. \& 35 other authors (1997). Genomic sequence of a Lyme disease spirochaete, Borrelia burgdorferi. Nature 390, 580-586.

Fuchs, R., Jauris, S., Lottspeich, F., Preac-Mursic, V., Wilske, B. \& Soutschek, E. (1992). Molecular analysis and expression of a Borrelia burgdorferi gene encoding a $22 \mathrm{kDa}$ protein $(\mathrm{pC})$ in Escherichia coli. Mol Microbiol 6, 503-509.

Gibbs, C. P., Livey, I. \& Dorner, F. (1996). The role of recombination in OspC variation in Lyme disease Borrelia. Acta Dermatovenereol Alpina Pannonica Adriatica 5, 179-183.

Higgins, D. G., Bleasby, A. J. \& Fuchs, R. (1992). CLUSTAL v: improved software for multiple sequence alignment. Comput Appl Biosci 8, 189-191.

Jauris-Heipke, S., Liegl, G., Preac-Mursic, V., Robler, D., Schwab, E., Soutschek, E., Will, G. \& Wilske, B. (1995). Molecular analysis of genes encoding outer surface protein $\mathrm{C}(\mathrm{OspC})$ of Borrelia burgdorferi sensu lato: relationship to ospA genotype and evidence of lateral gene exchange of ospC. J Clin Microbiol 33, 1860-1866.

Lam, T. T., Nguyen, T.-P. K., Montgomery, R. R., Kantor, F. S., Fikrig, E. \& Flavell, R. A. (1994). Outer surface proteins $E$ and F of Borrelia burgdorferi, the agent of Lyme disease. Infect Immun 62, 290-298.

Livey, I., Gibbs, C. P., Schuster, R. \& Dorner, F. (1995). Evidence for lateral transfer and recombination in OspC variation in Lyme disease Borrelia. Mol Microbiol 18, 257-269.

Maniatis, T., Fritsch, E. F. \& Sambrook, J. (1982). Molecular Cloning: a Laboratory Manual. Cold Spring Harbor, NY: Cold Spring Harbor Laboratory.

Marconi, R. T., Sung, S. Y., Norton Hughes, C. A. \& Carlyon, J. A. (1996). Molecular and evolutionary analyses of a variable series of genes in Borrelia burgdorferi that are related to ospE and ospF, constitute a gene family, and share a common upstream homology box. J Bacteriol 178, 5615-5626.

Martin, K. A., Davis, M. A. \& Austin, S. (1991). Fine-structure analysis of the P1 plasmid partition site. J Bacteriol 173, 3630-3634.

Motallebi-Veshareh, M., Rouch, D. A. \& Thomas, C. M. (1990). A family of ATPases involved in active partitioning of diverse bacterial plasmids. Mol Microbiol 4, 1455-1463.

Nguyen, T.-P. K., Lam, T. T., Barthold, S. W., Telford, S. R., III, Flavell, R. A. \& Fikrig, E. (1994). Partial destruction of Borrelia burgdorferi within ticks that engorged on OspE- or OspFimmunized mice. Infect Immun 62, 2079-2084.

Novick, R. P. (1987). Plasmid incompatibility. Microbiol Rev 51, 381-395.

Ogura, T. \& Hiraga, S. (1983). Partition mechanism of F plasmid: two plasmid gene-encoded products and a cis-acting region are involved in partition. Cell 32, 351-360.

Persing, D. H., Mathiesen, D., Podzorski, D. \& Barthold, S. W. (1994). Genetic stability of Borrelia burgdorferi recovered from chronically infected immunocompetent mice. Infect Immun 62, 3521-3527.

Porcella, S. F., Popova, T. G., Akins, D. R., Li, M., Radolf, J. D. \& Norgard, M. V. (1996). Borrelia burgdorferi supercoiled plasmids encode multi-copy tandem open reading frames and a lipoprotein gene family. J Bacteriol 178, 3293-3307.

Saint Girons, I. \& Davidson, B. E. (1992). Genome organization of Borrelia burgdorferi. In Lyme Disease: Molecular and Immunologic Approaches, pp. 111-118. Edited by J. Ingilis \& J. W. Sitkowski. Cold Spring Harbor, NY: Cold Spring Harbor Laboratory.

Simpson, W. J., Garon, C. F. \& Schwan, T. G. (1990a). Analysis of supercoiled circular plasmids in infectious and non-infectious Borrelia burgdorferi. Microb Pathog 8, 109-118.

Simpson, W. J., Garon, C. F. \& Schwan, T. G. (1990b). Borrelia burgdorferi contains repeated DNA sequences that are species specific and plasmid associated. Infect Immun 58, 847-853.

Stevenson, B. \& Barthold, S. W. (1994). Expression and sequence of outer surface protein C among North American isolates of Borrelia burgdorferi. FEMS Microbiol Lett 124, 367-372.

Stevenson, B., Bockenstedt, L. K. \& Barthold, S. W. (1994). Expression and gene sequence of outer surface protein $C$ of Borrelia burgdorferi reisolated from chronically infected mice. Infect Immun 62, 3568-3571.

Stevenson, B., Schwan, T. G. \& Rosa, P. A. (1995). Temperaturerelated differential expression of antigens in the Lyme disease spirochete, Borrelia burgdorferi. Infect Immun 63, 4535-4539.

Stevenson, B., Tilly, K. \& Rosa, P. A. (1996). A family of genes located on four separate 32-kilobase circular plasmids in Borrelia burgdorferi B31. J Bacteriol 178, 3508-3516.

Stevenson, B., Casjens, S., van Vugt, R., Porcella, S. F., Tilly, K., Bono, J. L. \& Rosa, P. (1997). Characterization of cp18, a naturally truncated member of the cp32 family of Borrelia burgdorferi plasmids. J Bacteriol 179, 4285-4291.

Stevenson, B., Bono, J. L., Schwan, T. G. \& Rosa, P. (1998). The Borrelia burgdorferi Erp proteins are immunogenic in tick-biteinfected mammals and their synthesis is inducible in cultured bacteria. Infect Immun (in press).

Suk, K., Das, S., Sun, W., Jwang, B., Barthold, S. W., Flavell, R. A. \& Fikrig, E. (1995). Borrelia burgdorferi genes selectively expressed in the infected host. Proc Natl Acad Sci USA 92, 4269-4273.

Theisen, M., Frederiksen, B., Lebech, A.-M., Vuust, J. \& Hansen, K. (1993). Polymorphism in ospC gene of Borrelia burgdorferi and immunoreactivity of OspC protein: implications for taxonomy and for use of $\mathrm{OspC}$ protein as a diagnostic antigen. $J \mathrm{Clin}$ Microbiol 31, 2570-2576.

Theisen, M., Borre, M., Mathiesen, M. J., Mikkelsen, B., Lebech, A.-M. \& Hansen, K. (1995). Evolution of the Borrelia burgdorferi outer surface protein OspC. J Bacteriol 177, 3036-3044.

Tilly, K., Casjens, S., Stevenson, B., Bono, J. L., Samuels, D. S., Hogan, D. \& Rosa, P. (1997). The Borrelia burgdorferi circular plasmid cp26: conservation of plasmid structure and targeted inactivation of the ospC gene. Mol Microbiol 25, 361-373.

Wallich, R., Brenner, C., Kramer, M. D. \& Simon, M. M. (1995). Molecular cloning and immunological characterization of a novel linear-plasmid-encoded gene, $p G$, of Borrelia burgdorferi expressed only in vivo. Infect Immun 63, 3327-3335.

Watanabe, E., Wachi, M., Yamasaki, M. \& Nagai, K. (1992). ATPase activity of SopA, a protein essential for active partitioning of F plasmid. Mol Gen Genet 234, 346-352. 
Wilske, B., Preac-Mursic, V., Schierz, G. \& Busch, K. V. (1986). Immunochemical and immunological analysis of European Borrelia burgdorferi strains. Zentralbl Bakteriol Hyg A 263, 92-102.

Xu, Y. \& Johnson, R. C. (1995). Analysis and comparison of plasmid profiles of Borrelia burgdorferi sensu lato strains. J Clin Microbiol 33, 2679-2685.

Zhang, J.-R., Hardham, J. M., Barbour, A. G. \& Norris, S. J. (1997). Antigenic variation in Lyme disease borreliae by promiscuous recombination of VMP-like sequence cassettes. Cell 89, 1-20.

Zückert, W. R. \& Meyer, J. (1996). Circular and linear plasmids of
Lyme disease spirochetes have extensive homology: characterization of a repeated DNA element. J Bacteriol 178, 2287-2298.

Zückert, W. R., Filipuzzi-Jenny, E., Meister-Turner, J., Stålhammar-Carlemalm, M. \& Meyer, J. (1994). Repeated DNA sequences on circular and linear plasmids of Borrelia burgdorferi sensu lato. In Lyme Borreliosis, pp. 253-260. Edited by J. S. Axford \& D. H. E. Rees. New York: Plenum Press.

Received 19 November 1997; revised 20 February 1998; accepted 2 March 1998. 